\title{
Lc-Ms Oxycodone Study: Its Stability in Anapa Devices
}

\author{
Amodio $\mathrm{L}^{1}$, Nardulli $\mathrm{P}^{2 *}$, Ferraiuolo $\mathrm{S}^{2}$, Leonetti $\mathrm{F}^{3}$, Lacivita $\mathrm{E}^{3}$, Leopoldo, $\mathrm{M}^{1,3}$, Colabufo $\mathbf{N} \mathrm{A}^{1,3 *}$ and Jean \\ Carlo Marchio ${ }^{4}$ \\ ${ }^{1}$ Biofordrug, spin-off of the University of Bari, Italy \\ ${ }^{2} S$ C Pharmacy and U.Ma.C.A, IRCCS, G Paolo II Tumor Institute, Italy
}

${ }^{3}$ Department of Pharmacy-Pharmaceutical Sciences, University of Bari, Italy

${ }^{4}$ Ewha Meditech, Korea

*Corresponding author: Patrizia Nardulli, S C Pharmacy and U.Ma.C. A, IRCCS, G Paolo II Tumor Institute, Italy

Nicola Antonio Colabufo, Biofordrug, spin-off of the University of Bari, Department of Pharmacy- Pharmaceutical Sciences, University of Bari, Italy

\begin{tabular}{|c|c|}
\hline ARTICLE INFO & ABSTRACT \\
\hline Received: 幽 January 23, 2020 & Anapa is a medical device for infusion that uses $\mathrm{CO} 2$ self-produced as power source. \\
\hline Published: 幽 January 31, 2020 & $\begin{array}{l}\text { Oxycodone is an analgesic drug belonging morphine derivatives employed frequently to } \\
\text { manage cancer pain since with respect to morphine displays minor side effects. In the }\end{array}$ \\
\hline $\begin{array}{l}\text { Citation: Amodio L, Nardulli P, Ferraiuolo } \\
\text { S, Leonetti F, Lacivita E, Leopoldo, M, } \\
\text { Colabufo N A, Jean Carlo Marchio. Lc-Ms }\end{array}$ & $\begin{array}{l}\text { studied experimental condition. At low concentration, at } 24 \mathrm{~h} \text {, peaks due to degradation } \\
\text { of drug or due to interaction with medical device are not detected. The concentration } \\
\text { resulted lower than initial study only in this case because of adducts. }\end{array}$ \\
\hline
\end{tabular}

Oxycodone Study: Its Stability in Anapa Devices. Biomed J Sci \& Tech Res 25(2)-

Keywords: Anapa; Oxycodone; LC-MS; Drug Stability

2020. BJSTR. MS.ID.004165.

\section{Introduction}

Anapa is the world's first and unique disposable infusion device using self-produced $\mathrm{CO}_{2}$ as power source. By its unique design, it is safe of the many shortcomings of mechanical, electronic and elastomeric devices. It offers the best combination of accuracy, safety and convenience in pain palliation. In this medical device, drug stability evaluation is needed to verify the compatibility of polycarbonate surface of Anapa's body with several drugs handled in hospitals. In the present study, the oxycodone stability is reported at different concentrations ranging from $1 \mathrm{mg} / \mathrm{mL}$ to $8 \mathrm{mg} / \mathrm{mL}$ and at two different temperature $\left(25^{\circ} \mathrm{C}\right.$ and $\left.33^{\circ} \mathrm{C}\right)$. Oxycodone is an analgesic drug belonging morphine derivatives and it is employed frequently to manage cancer pain since with respect to morphine displays minor side effects. For this reason, oxycodone is considered a viable alternative to morphine and so the first line treatment of cancer pain [1]. The aim of this report is to study the stability of Oxycodone Hydrochloride in Anapa Anaplus disposable pump in Normal Saline (NS), at storage periods and temperatures similar to those the drug is usually prepared and stored in Pharmacies and Hospitals for administration to patients [2]. This report is carried out in collaboration with the Unit of Antineoplastic Drug Handling (U.Ma.CA.) of the Cancer Institute "Giovanni Paolo II", Bari. In particular, oxycodone hydrochloride solution, $1,17 \mathrm{mg} / \mathrm{mL}$ in $\mathrm{NS}, 3,57 \mathrm{mg} / \mathrm{mL}$ in $\mathrm{NS}$ and $8,64 \mathrm{mg} /$ $\mathrm{mL}$ in NS have been studied in Anapa Anaplus disposable pump. The studies were carried out at $25^{\circ} \mathrm{C}$ at $0 \mathrm{~h}, 12 \mathrm{~h}$ and $24 \mathrm{~h}$. The polycarbonate surface of ANAPA's body and the line are touched by drug for each studied concentration. In all performed studies, the stability-indicating method involves the use of LC-MS/MS analysis allowing an unambiguous assessment of drug purity, stability and compatibility with medical devices $[3,4]$.

\section{Filling Procedures}

The filling procedure of medical device was executed according to the protocols of the Unit of Antineoplastic Drug Handling (U.Ma.CA.) of the Cancer Institute "Giovanni Paolo II", Bari. The manipulation was performed in accordance with international 
standard guidelines on injectable. Oxycodone Hydrochloride for these studies has been gifted by Molteni Farmaceutici S.P.A In (Table 1) are reported the studied solutions and the other experimental parameters. The collection was carried out directly by the terminal part of the plastic infusion line in a tube and then the solution was transferred into vials for LC-MS/MS analysis. The samples were used after dilution in LC-MS/MS Analysis.

Table 1: Experimental study.

\begin{tabular}{|c|c|c|c|}
\hline Concentration & $\mathbf{1 . 1 7} \mathbf{~ m g / \mathbf { m L }}$ & $\mathbf{3 , 5 7} \mathbf{~ m g} / \mathbf{m L}$ & $\mathbf{8 . 6 4} \mathbf{~ m g} / \mathbf{m L}$ \\
\hline Diluent & Normal saline & Normal saline & Normal saline \\
\hline Devices & 2 & 2 & 2 \\
\hline Temperature & $25^{\circ} \mathrm{C}$ and $33^{\circ} \mathrm{C}$ & $\begin{array}{c}25^{\circ} \mathrm{C} \text { and } \\
33^{\circ} \mathrm{C}\end{array}$ & $25^{\circ} \mathrm{C}$ and $33^{\circ} \mathrm{C}$ \\
\hline Time points & $0 \mathrm{~h} .12 \mathrm{~h}, 24 \mathrm{~h}$ & $0 \mathrm{~h} .12 \mathrm{~h}, 24 \mathrm{~h}$ & $0 \mathrm{~h} .12 \mathrm{~h}, 24 \mathrm{~h}$ \\
\hline
\end{tabular}

\section{Material and Methods}

\section{Liquid Chromatograph Mass Spectrometer Apparatus}

Liquid Chromatograph Mass Spectrometer Analyses were performed on a Shimadzu LCMS-8040 Trip Quad MS equipped with System Controller CBM-20A, Trip Quad Mass Spectrometer detector and controlled by LabSolutions WS Software. The employed column was a Luna $\AA^{\circ}$ Omega $5 \mu \mathrm{m}$ PS C18 100 Å column dimensions 150x4.6 mm, column from Phenomenex QC MIX 870. LC-MS/ MS operating conditions (Flow, Mobile phase, Injection volume, Retention time, Column temperature, Condition of detection) are following reported.

\section{Chemicals}

All chemicals and reagents were of the highest purity. All solvents were UPLC grade quality and all chemicals were purchased from Honeywell Riedel-de-Haën.

\section{LC-MS/MS Apparatus}

Shimadzu LCMS-8040, Column: Luna ${ }^{\circledR}$ Omega $5 \mu \mathrm{m}$ PS C18 $100 \AA ̊$ Å column dimensions 150x4.6 mm, column from Phenomenex QC MIX 870. Detector: Trip Quad Mass Spectrometer. Flow: 0.18 $\mathrm{mL} / \mathrm{min}$. Mobile phase: MeOH:Water (5 mM ammonium formate with $\mathrm{pH}=9.4$, adjusted with $25 \%$ ammonium hydroxide solution). Injection volume: $7 \mu \mathrm{L}$, the retention time was about about 8.1. The column temperature was $50^{\circ} \mathrm{C}$. The samples, taken on the indicated hours, were used, after dilution, for LC-MS/MS injection.

\section{Calibration curve}

The calibration curve and the chromatogram, respectively, are reported in (Figure 1), each point is the mean of duplicate injection at the gave concentration.

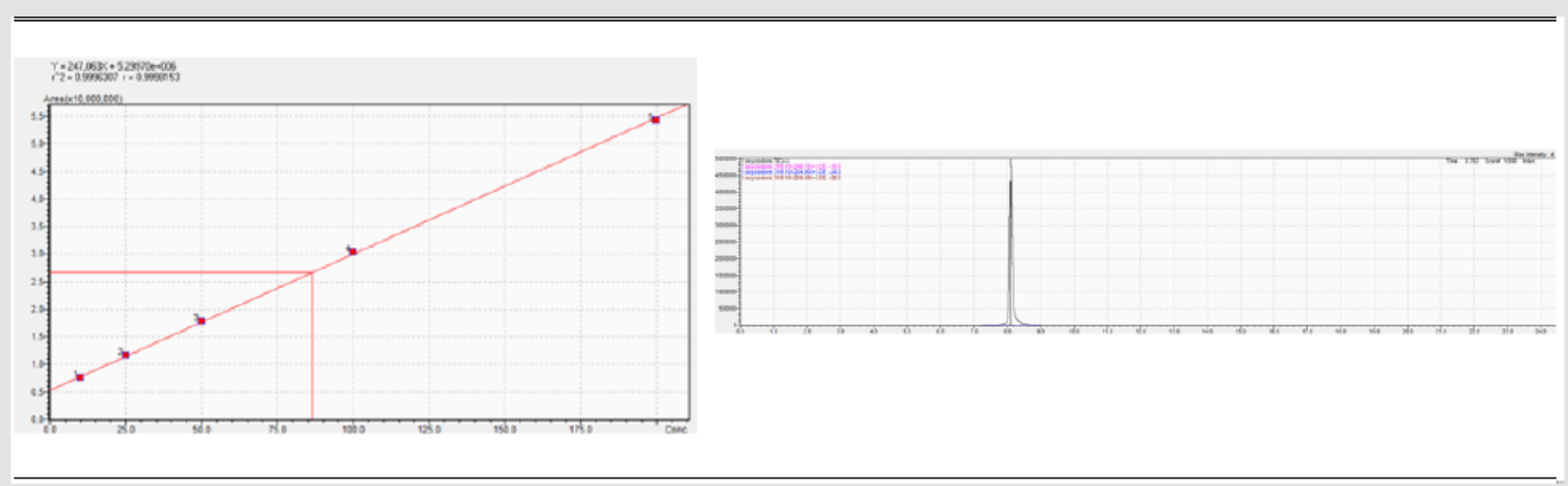

Figure 1: Oxycodone calibration curve and chromatogram.

\section{Results}

In this study the employed method involved the use of LCMS/MS analysis. The samples were taken over the studied period and submitted to LC-MS/MS analysis allowing an unambiguous assessment of drug purity, stability and compatibility. The used procedure for establishing purity and stability of the tested drug was to compare the LC-MS/MS results with that of a reference solution. For the quantitative evaluation, the areas of peak under interest have been compared with that of reference solutions to appreciate the stability of drug concentration during the period of analysis. Final quantitative results are reported in term of "average concentration" and "\% concentration" of samples considering the starting concentration measured at $t=0$ from 12 hours, and then 24 hours. Quantitative analyses were executed by using the external standard method to construct a calibration curve (see experimental section) for the calculation of the concentrations. For the qualitative evaluation the LC-MS/MS of all samples have been compared with the results obtained with a standard solution of the drug. Moreover, particular attention was given to the monitoring of color and clarity of the solution into the device and into the taken samples. The collected samples were limpid solutions and the $\mathrm{pH}$ was measured.

The study of $\%$ variation of concentration has been employed to appreciate the stability of drug concentration during the requested period of observation. As reported in the (Table 2A-2B), acceptable variability in terms of concentration $(<5 \%)$ was observed until $24 \mathrm{~h}$ after the loading procedure and at the all experimental conditions. 
Oxicodone solution $1,17 \mathrm{mg} / \mathrm{mL}$, is stable until $12 \mathrm{~h}$ both at $\mathrm{T}=$ $25^{\circ} \mathrm{C}$ and $\mathrm{T}=33^{\circ} \mathrm{C}$ whereas at $24 \mathrm{~h}$, a significant difference in term of $\%(>>5 \%)$ with respect solution at $\mathrm{T}=0$ are reported for both temperatures (Table 2). The other concentrations 3,57 $\mathrm{mg} / \mathrm{mL}$ and $8,64 \mathrm{mg} / \mathrm{mL}$ are stable at every time point and for each measured temperature as reported in (Tables 3 \& Table 4), respectively.

Table 2: Oxycodon 1,17 mg/mL ( $\mathrm{pH}=6,87)$.

\begin{tabular}{|c|c|c|c|}
\hline Temperature & Time (h) & Average Concentration (1,17 mg/mL) & Average Concentration change (\%) \\
\hline & 0 & $1,17 \pm 0,07$ & 0 \\
\hline $25^{\circ} \mathrm{C}$ & 12 & $1,16 \pm 0.05$ & $+0,71$ \\
\hline $25^{\circ} \mathrm{C}$ & 24 & $0.94 \pm 0.08$ & 0 \\
\hline & 0 & $1,17 \pm 0,07$ & $+4,04$ \\
\hline $33^{\circ} \mathrm{C}$ & 12 & $1,22 \pm 0.05$ & $+18,53$ \\
\hline
\end{tabular}

Table 3: Oxycodon 3,57 mg/mL (pH = 6,48).

\begin{tabular}{|c|c|c|c|}
\hline Temperature & Time (h) & Average Concentration (3,57 $\mathbf{~ m} / \mathbf{m L})$ & Average Concentration change (\%) \\
\hline & 0 & $3,57 \pm 0,07$ & 0 \\
\hline $25^{\circ} \mathrm{C}$ & 12 & $3,55 \pm 0.04$ & $+3,10$ \\
\hline $25^{\circ} \mathrm{C}$ & 24 & $3.46 \pm 0.07$ & 0 \\
\hline & 0 & $3,57 \pm 0,07$ & $+0,51$ \\
\hline $33^{\circ} \mathrm{C}$ & 12 & $3,55 \pm 0.05$ & $+3,10$ \\
\hline
\end{tabular}

Table 4: Oxycodon 8,64 mg/mL $(\mathrm{pH}=6,64)$.

\begin{tabular}{|c|c|c|c|}
\hline Temperature & Time (h) & Average Concentration (8,64 mg/mL) & Average Concentration change (\%) \\
\hline & 0 & $8,64 \pm 0,07$ & $+0,34$ \\
\hline $25^{\circ} \mathrm{C}$ & 12 & $8,67 \pm 0.05$ & $+4,00$ \\
\hline $25^{\circ} \mathrm{C}$ & 24 & $8,99 \pm 0.07$ & 0 \\
\hline & 0 & $8,64 \pm 0,07$ & $+0,34$ \\
\hline $33^{\circ} \mathrm{C}$ & 12 & $8,94 \pm 0.05$ & $+4,00$ \\
\hline
\end{tabular}

\section{Discussion}

ANAPA disposable infusion device employed self-produced $\mathrm{CO}_{2}$ as power source. In this way offers the best combination of accuracy, safety and convenience in pain palliation. The drug stability studies with oxycodone demonstrated that the polycarbonate surface of ANAPA's body is suitable for Oxycodone stability in each experimental condition excepting for the lowest concentration at $24 \mathrm{~h}$. LC-MS/MS studies demonstrated that other peaks due to degradation of drug and/or to medical device-drug interaction are not detected, adopts are assumed to have formed which significantly influenced the concentration being lower than the previous ones. This aspect is evident comparing the spectrum at $0 \mathrm{~h}$ (top) and $24 \mathrm{~h}$ (bottom) for oxycodone 1,17 mg/mL (Figure 2) In conclusion LC-MS is a suitable and robust strategy to study drug stability of oxycodone and Anapa disposable is an innovative infusion device and the material is well tolerated both with different drug concentrations and different temperature. 

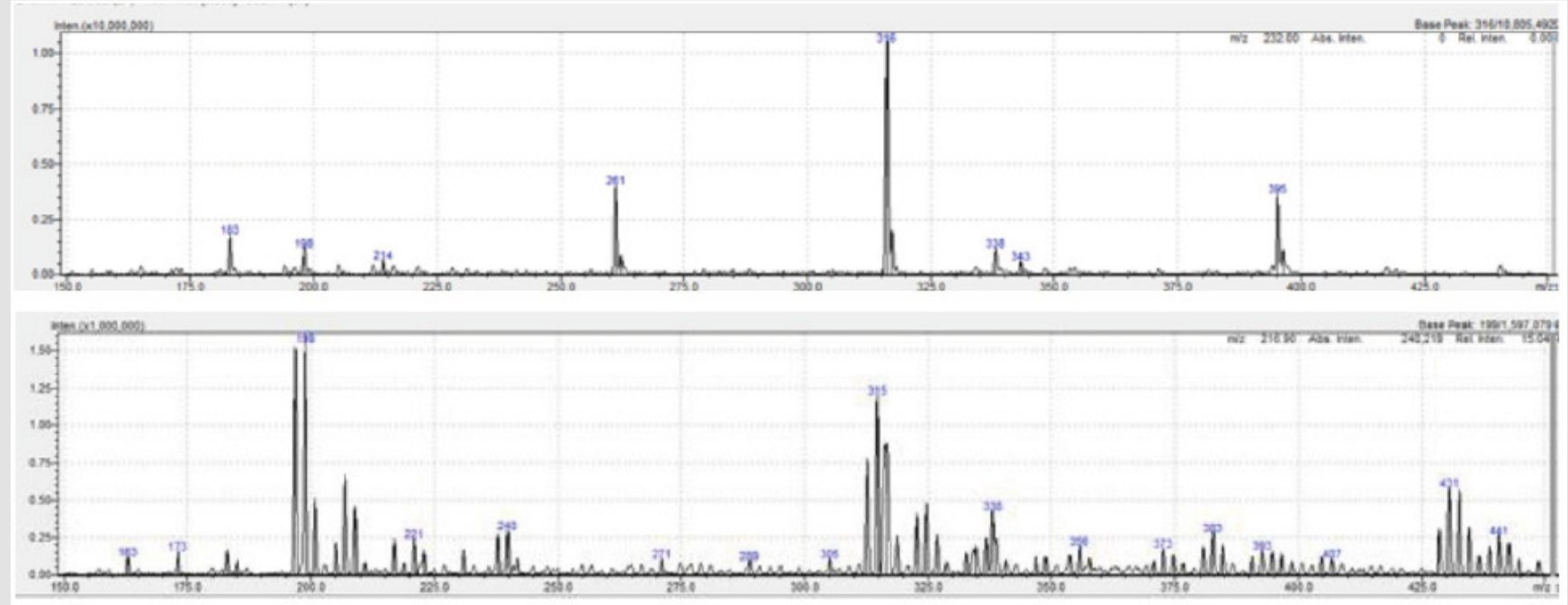

Figure 2: Oxycodone fragment at o h and $24 \mathrm{~h}$.

\section{References}

1. Clark K, Byrne PG, Humt J, Brown L, Rowett D, et al. (2020) Pharmacovigilance in Hospice/Palliative Care: De-Prescribing Combination Controlled Release Oxycodone-Naloxone. J Palliat Med.

2. Yamamoto PA, Conchon Costa AC, Lauretti G R, De Moreas NV (2019) Pharmacogenomics in chronic pain therapy: from disease to treatment and challenges for clinical practice. J Palliat Med 20(13).

\section{ISSN: 2574-1241}

DOI: $10.26717 / B J S T R .2020 .25 .004165$

Nardulli P. Biomed J Sci \& Tech Res

(C) This work is licensed under Creative

Submission Link: https://biomedres.us/submit-manuscript.php
3. Neuvonen M, Neuvonen PJ (2008) Determination of Oxycodone, Noroxycodone,Oxymorphone and Noroxymorphone in Human Plasma by Liquid Chromatography-Electrospray-Tandem Mass Spectrometry. Ther Drug Monit 30(3): 333-340.

4. Ramirez Fernandez MDM, Wille SMR, Jankowsli D, Samyn N (2019) Development of an UPLC-MS/MS method for the analysis of 16 synthetic opioids in segmented hair, and evaluation of the polydrug history in fentanyl analogue users. Forensic Sci int.

\begin{tabular}{ll} 
BIOMEDICAL & Assets of Publishing with us \\
RESEARCHES & - Global archiving of articles \\
& - Immediate, unrestricted online access \\
\hline ISSN: $2574-1241$ & - Rigorous Peer Review Process \\
\end{tabular}

